\title{
Formation of the International Fossil Fuel Agency (IFFA) as A Logical Proposal for Exiting from the Environmental Crisis of the Century
}

\author{
Seyed Mostafa Hosseini Asl* \\ Department of Chemical Engineering, Islamic Azad University, Iran
}

*Corresponding author: Seyed Mostafa Hosseini Asl, Department of Chemical Engineering, Islamic Azad University, Ayatollah Amoli Branch, Amol, Iran

\section{Mini Review of Recent Studies}

Increasing industrialization speed particularly among developing countries has been led to the influx of governments into available natural resources and consequently our planet has been facing with more environment destruction during recent years. From other side, the unfair competition for higher economic productivity between industrialized countries has created endless demand for generation of energy from traditional fossil fuels. The mankind manipulation in the environment under the pretext of industrialization caused to unwanted phenomena such as emissions of more greenhouse gases to the environment, air pollution, global warming, climate changes, water pollutions and etc. Among fossil fuels, coal is still as cheapest source of energy due to its abundance in many countries. According to the published outlook in 2017 by energy information administration (EIA), until 2040 the rate of coal consumption worldwide will rapidly enhance, and this means production of more greenhouse gases, air pollution and coal fly ash (CFA). The number of coal-fired power plants in the EU and US are more than 300 and nearly 175, respectively [1]. The most important consumers of coal in the world are including China, India, Canada, the former Soviet republics, some of East Asia, South Africa and South America countries. In order to overcome this critical situation, the amount of coal consumption in all around the world should be reduced to allow our planet to breathe again (Figure 1).

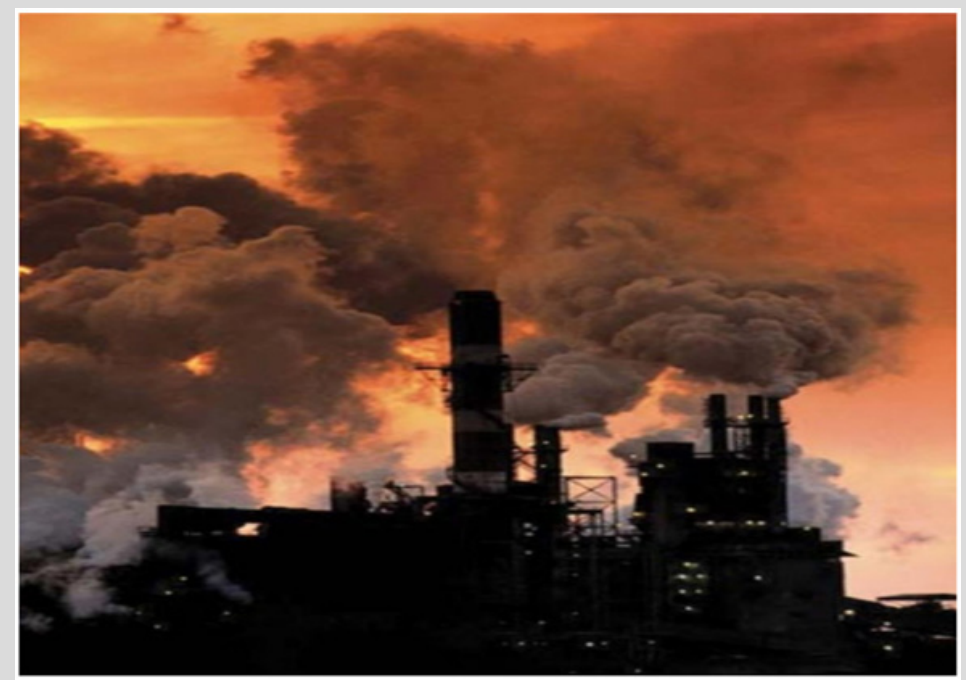

Figure 1: The Emission of Greenhouse Gasses by Coal-Fired Power Plants. 
Generally, there are three points of views regarding this issue. Unlike the environmental activists and people those whom are deeply concern from this conditions and believe that all the coalfired power plants must be shut down, the politicians are strictly disagree with this comment because it can lead to some negative results like reduction of national production, fiscal crises and growth of unemployment. On the other hand, the scientific researchers have been working on this problem several years (Figure 2a). They are trying to find an appropriate answer to the presented question which is recognized as the biggest challenge of our century. The question is: "Is there any logical solution to produce clean energy from fossil fuels specifically from coal? Although, many researches have conducted on the capture and storage technologies (CST) as one of the most efficient methods to prevent the gaseous and dust pollutions, but this proposed technology is still expensive to be use in all coal-fired power plants. Achieving clean energy from coal will be possible if affordable technologies become widespread throughout the world (Figure $2 \mathrm{~b}$ ). In recent years, the researchers are focused on obviating this drawback of CST (Capture and Storage Technologies) through conversion of waste materials to the valueadded products for both industrial and environmental purposes.

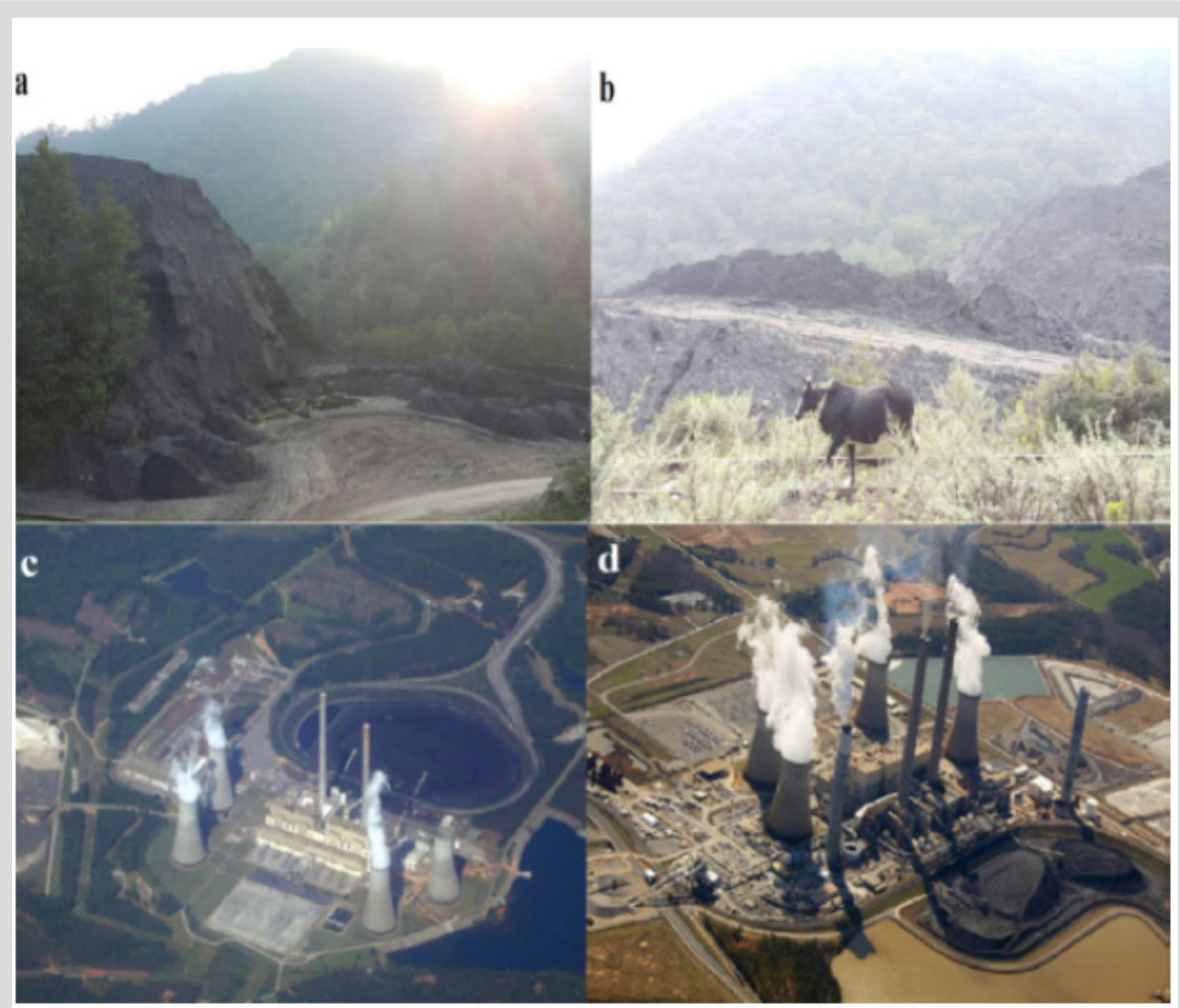

Figure 2: a) Production of coal ash in a coal mine site (The mountain contains coal ash more than two million tons). b) The negative effects of CFA accumulation on the environment (destruction of natural eco-system), Savadkouh, Mazandaran, Iran. c) CFA emission into the air and environment by coal-fired power plant in Georgia. D) Accumulation of coal fly ash in the landfills around Georgia coal-fired power plant.

CFA is a byproduct of coal combustion process particularly in coal-fired power plants which is considered as one of the important hazards for both eco-system and living organisms. This waste solid material contains valuable aluminosilicate sources with honeycomb structure, high porosity and large surface area [2]. These unique properties have attracted the researcher's attentions to manufacture of efficient, economical and eco-friendly adsorbents from CFA. Some of outstanding research works in the field of CFA are production of zeolitic/catalytic/geo-polymeric adsorbents for medical, environmental and industrial consumptions, thermal isolator, glass ceramics, chemical fertilizers and etc. One of the most interesting areas of CFA applications is in climate engineering program through pore condensation and freezing (PCF) mechanism. The investigations show that CFA particles play a significant role in cloud formation as a chemical ice nucleation. Therefore, these carried out efforts by researchers clearly illustrates that they are in right direction to find the best answer for the mentioned question
(Figure 2c). Since, the time for reaching to the solution is not clear, we need to prevent from dangerous events derived from fossil fuels. The formation of an international organization to monitor and control of the air pollution caused by fossil fuels is necessary. The linkage of people, researchers and the decision makers from all around the world in the form of an international organization (IFFA) can help to more coordination and cooperation among them to have healthy ecosystems for our planet (Figure 2d). The IFFA can act through approval of incentive and punitive laws applicable for all countries that use from fossil fuels. All the countries should attend to IFFA and be under its supervision till they can use from its financial and scientific services. In addition, the IFFA should convince the governments to more supports of research works in the area of production of clean energy from fossil fuels. Ultimately, the promotion new technologies usable in new generation of coalfired power plants by IFFA will effectively decrease the pollution of fossil fuels. 


\section{References}

1. SM Hosseini Asl, H Javadian, M Khavarpour, C Belviso, M Taghavi, et al. (2019) Porous adsorbents derived from coal fly ash as cost-effective and environmentally friendly sources of aluminosilicate for sequestration of aqueous and gaseous pollutants: A review. J Cleaner Prod 208: 11311147.
2. SM Hosseini Asl, A Ghadi, M Sharifzadeh Baei, H Javadian, M Maghsudi, et al. (2018) Porous catalysts fabricated from coal fly ash as cost-effective alternatives for industrial applications: A review. Fuel 217: 320-342.

\section{(cC)

To Submit Your Article Click Here: Submit Article

DOI: $10.32474 /$ RRHOAJ.2019.03.000170

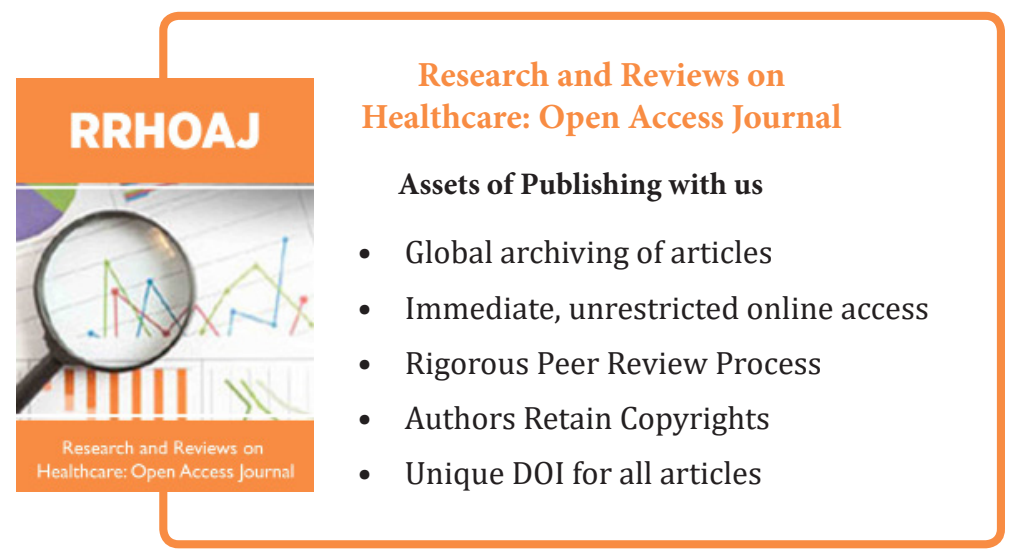

